\title{
Quantifying drivers of variability in life cycle greenhouse gas emissions of consumer products-a case study on laundry washing in Europe
}

\author{
Sadegh Shahmohammadi ${ }^{1}$ - Zoran Steinmann ${ }^{1}$ - Julie Clavreul ${ }^{2} \cdot$ Hilde Hendrickx $^{3} \cdot$ Henry King $^{2}$. \\ Mark A. J. Huijbregts ${ }^{1}$
}

Received: 4 May 2017 / Accepted: 30 November 2017 / Published online: 22 December 2017

(C) The Author(s) 2017. This article is an open access publication

\begin{abstract}
Purpose Variability in consumer behaviour can significantly influence the environmental performance of products and their associated impacts and this is typically not quantified in life cycle assessments. The goal of this paper is to demonstrate how consumer behaviour data can be used to understand and quantify the variability in the greenhouse gas emissions from domestic laundry washing across Europe.

Methods Data from a pan-European consumer survey of product usage and washing habits was combined with internal company data on product format greenhouse gas (GHG) footprints and in-home measurement of energy consumption of laundry washing as well as literature data to determine the GHG footprint of laundry washing. The variability associated with four laundry detergent product formats and four wash temperature settings in washing machines were quantified on a per wash cycle basis across 23 European countries. The variability in GHG emissions associated with country electricity grid mixes was also taken into account. Monte Carlo methods were used to convert the variability in the input parameters into variability of the life cycle GHG emissions. Rank correlation analysis was used to quantify the importance of the different sources of variability.

Results and discussion Both inter-country differences in background electricity mix as well as intra-country variation in consumer behaviour are important for determining the variability in life cycle GHG emissions of laundry detergents. The average GHG emissions related to the laundry washing process in the 23 European countries in 2014 was estimated to be $5 \times 10^{2} \mathrm{~g} \mathrm{CO}_{2}$ _eq/wash cycle, but varied by a factor of 6.5 between countries. Intra-country variability is between a factor of 3.5 and $5.0(90 \%$ interval). For countries with a mainly fossil-based electricity system, the dominant source of variability in GHG emissions results from consumer choices in the use of washing machines. For countries with a relatively low-carbon electricity mix, variability in life cycle GHG emissions is mainly determined by laundry product-related parameters.

Conclusions The combination of rich data sources enabled the quantification of the variability in the life cycle GHG emissions of laundry washing which is driven by a variety of consumer choices, manufacturer choices and infrastructural differences of countries. The improved understanding of the variability needs to be balanced against the cost and challenges of assessing of consumer habits.
\end{abstract}

Responsible editor: Serenella Sala

Electronic supplementary material The online version of this article (https://doi.org/10.1007/s11367-017-1426-4) contains supplementary material, which is available to authorized users.

Sadegh Shahmohammadi

sadeghs@science.ru.nl

1 Department of Environmental Science, Institute for Water and Wetland Research, Radboud University Nijmegen, PO Box 9010, 6500GL Nijmegen, The Netherlands

2 Unilever Safety and Environmental Assurance Centre, Colworth Science Park, Sharnbrook, Bedford MK44 1LQ, UK

3 Unilever Discover, Colworth Science Park, Sharnbrook, Bedford MK44 1LQ, UK
Keywords Consumer behaviour - Carbon footprinting . Greenhouse gas emissions · Laundry products · Life cycle assessment $\cdot$ Variability

\section{Introduction}

Consumer choice and behaviour can be highly variable and a major contributor to the environmental impact of typical household activities such as washing, cleaning, cooking and entertainment (Throne-Holst et al. 2007). Interactions between consumers and products may have a large effect on the overall results of life cycle assessment (LCA) studies. However, the variability in consumer behaviour is often not 
included in LCAs because these are generally aimed at quantifying the average impact of a process or a product rather than the full extent of possible outcomes like in environmental risk assessment methods. This has been identified as a key gap in LCA (Polizzi di Sorrentino et al. 2016; Hellweg and Milà i canals 2014). According to a study on 38 countries, clothes washing (excluding tumble drying and ironing) is among the major energy-demanding household activities, accounting for up to $17 \%$ (in Turkey) of the total domestic energy consumption (Pakula and Stamminger 2010).

A summary of the key variables that influence the greenhouse gas footprint of laundry washing, categorised as consumer-related, laundry detergent manufacturer-related and energy grid-related is shown in Fig. 1.

Consumer behaviour can influence the greenhouse gas (GHG) emissions associated with clothes washing in several ways. The contribution of consumer behaviour to variability in the GHG emissions can be classified in two categories namely (1) product-related parameters, including choice of detergent format (e.g., powder, liquid) and dose and (2) machine-related parameters, such as choice of wash program and temperature, load size and energy efficiency of washing machines. When a consumer chooses a laundry detergent product, the environmental impacts of this product are determined by the choices that were made by the manufacturer in terms of product design, manufacturing, sourcing and supply chain. For example, Saouter et al. (1998) argued that although more energy is consumed in the supply phase of liquid laundry detergents, the energy consumption during their use phase is lower in comparison to powder detergents. Furthermore, Nielsen et al. (2013) concluded that compaction can lead to less

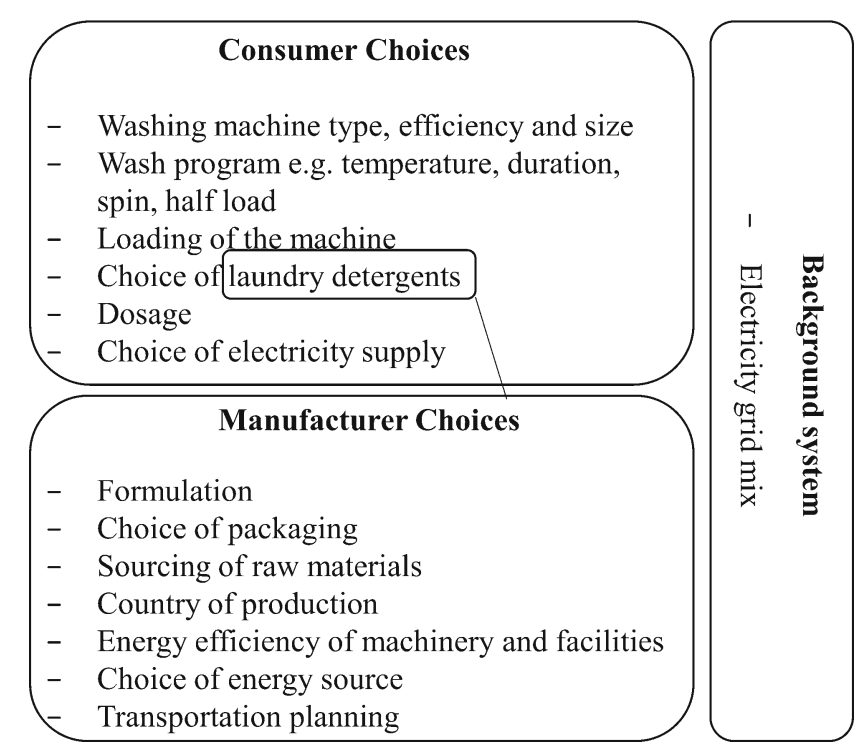

Fig. 1 Variables influencing the life cycle GHG emissions of laundry washing emissions from both powder and liquid laundry detergents in each wash cycle.

Regardless of the format and amount of detergent used, energy use in washing machines ranges from $0.1 \mathrm{kWh} /$ cycle (Pakula and Stamminger 2010) to $2.3 \mathrm{kWh} / \mathrm{cycle}$ (Tomlinson and Rizy 1998). In particular, energy consumption of washing machines in different countries has been reported in a number of studies such as AISE (2013), Koerner et al. (2011), Laitala et al. (2011), Lin and Iyer (2007), Market Transformation Programme (2010), Masanet (2010), Novem (2001), Pakula and Stamminger (2015), Presutto et al. (2007), Yao and Steemers (2005) and Zaraket (2014). Inter-country variability arises from the differences in the GHG footprint of the electricity grid mixes and systematic differences in consumer behaviour in different countries. Depending on the source of energy used to generate electricity for households, either the consumer use phase or the ingredients supply phase may have the highest share of GHG emissions during the life cycle of products (Dewaele et al. 2006; Medyna et al. 2015). This means both the product-related as well as the machine-related choices can be the dominant influencers of the variation in GHG emissions related to clothes washing. Although the LCA studies on laundry detergents and clothes washing provide insights into individual sources of variability, they do not provide a systematic comparison of the influence of the different sources of variability on the GHG emissions.

The main objective of this paper is to demonstrate how a combination of consumer behaviour data (e.g., survey data and technical observations) can be used to quantify the variability of the GHG impacts of a typical household activity, namely the laundry of clothes and other items. We quantified the influence of consumer behaviour on the variability in GHG emissions from clothes washing across European countries. Consumer survey data from a pan-European study were used (AISE 2014), combined with in-home washing machine energy studies using data loggers (715 observation/100 households) and GHG data on laundry detergent products. We focused on GHG emissions which is one of the key impacts of laundry activity (Golsteijn et al. 2015; Koehler and Wildbolz 2009; de Koning et al. 2010; AISE 2015). A Monte Carlo simulation (Rubinstein and Kroese 2016) was used to quantify the variability in GHG footprints of laundry washing due to variability in (i) detergent format, (ii) detergent dosage (actual), (iii) GHG emissions related to detergent production, (iv) wash temperature, (v) machine energy use within a range of temperature settings and (vi) country electricity grid mixes. In addition, we investigated the GHG emissions' variability in a scenario in which the required electricity for washing machines was produced from solar PV. 


\section{Methods}

\subsection{Data sources}

Table 1 summarises the sample size and type of data used to assess variability in the GHG footprint of a laundry wash in 2014 across 23 European countries including its temporal, geographical and product representativeness. Tables S1 and S2 and Fig. S1 of the Electronic Supplementary Material $(\mathrm{ESM})$ provide more detailed information on the data.

In 2014, the International Association for Soaps, Detergents and Maintenance Products (AISE) commissioned a Pan-European consumption survey on sustainability and washing habits. The survey gathered information on washing habits and their evolution in the domains of laundry and dishwashing practices using an online questionnaire. Four thousand seven hundred forty-one men, and women aged 18-65, responsible for purchase and using a laundry machine were recruited via panels in 23 European countries. The relative frequency of use of the four main laundry detergent formats, i.e. powder, liquids, tablets and capsules was estimated from the type of laundry detergent used by respondents for normal washing over a 3-month period. The AISE study also reports the probability of use of the temperature settings ' $30^{\circ} \mathrm{C}$ or lower', ' $40{ }^{\circ} \mathrm{C}$ ', ' $50^{\circ} \mathrm{C}$ ', and ' $60^{\circ} \mathrm{C}$ or higher' per country which we used in our study.

The GHG emissions of laundry detergents vary by formulation, pack size, transportation and producer. An in-house dataset of GHG emissions for laundry detergents manufactured by Unilever in 2014 was used to estimate the variability in the GHG emissions ( $\mathrm{g} \mathrm{CO}_{2}-\mathrm{eq} / \mathrm{g}$ detergent) of the four detergent formats in Europe. Unilever is one of the major laundry detergent manufacturers in Europe with sales of powders, liquids and capsules with varying market share depending upon consumer preferences.

The consumer habit in actual dosing of powder, liquid and tablet laundry detergents was based on a comprehensive study performed in Germany (Kruschwitz et al. 2014). In the absence of comparable data for all countries, we assumed that the variability in product dosing measured in Germany was representative for all countries. For the dosing of capsule laundry detergents, no empirical studies on consumer habits were available so we assumed that consumers use the recommended dosage of one capsule per wash cycle.

The variability in the energy consumption of washing machines for the specified temperature ranges was quantified using data from a field investigation exploring laundry habits over 100 UK households (Unilever, internal data, 2014). The study involved simultaneous collection of technical wash data using an advanced logger technology to record real wash information (i.e. duration, energy use and temperature setting) of 715 wash cycles. We developed probability distributions of energy consumptions associated with the following

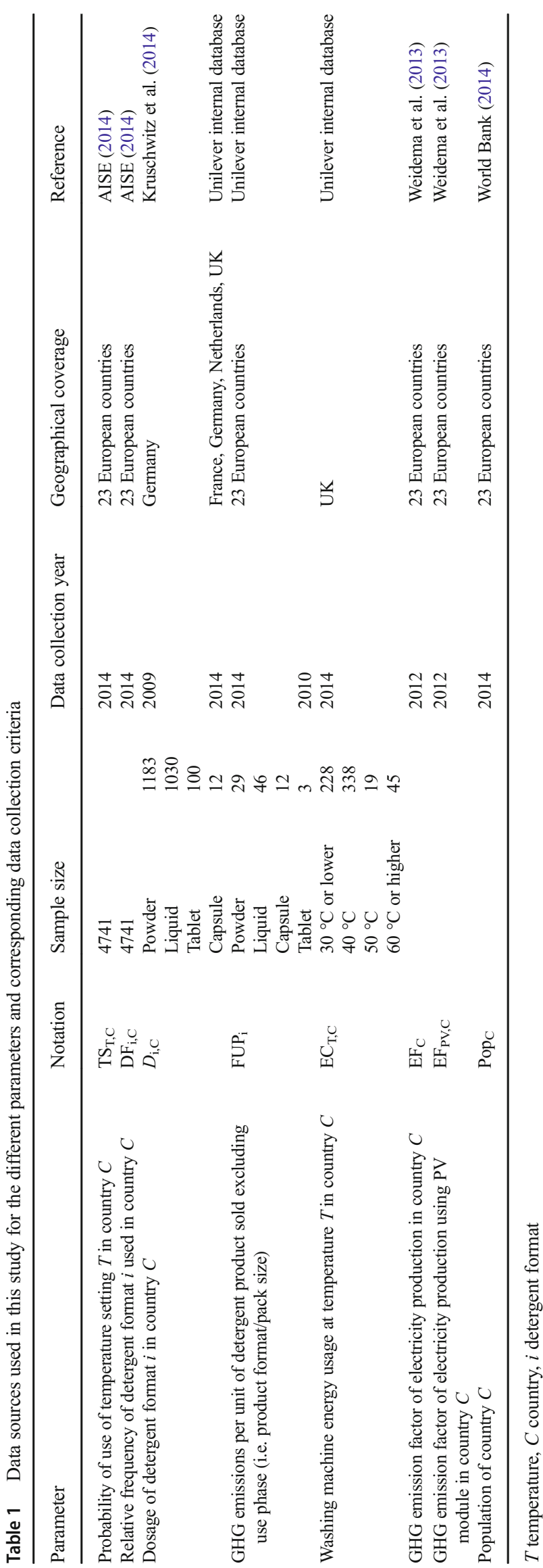


temperatures ranges 30 or lower, 40,50 and $60{ }^{\circ} \mathrm{C}$ or higher that were reported in the AISE habits survey. The variability observed for each temperature range is driven by the duration of the wash, load size and the energy efficiency of the washing machine. Wash cycles with a duration over $200 \mathrm{~min}$ or shorter than $20 \mathrm{~min}$ (12\% of the total number of washes) were considered as outliers and were excluded. In the absence of comparable data for all countries, the variability in energy use measured in the UK study was considered representative for the other countries included. For the country-specific GHG emissions per kilowatt hour electricity produced, we used the ecoinvent database (version 3.2, Weidema et al. 2013) that provides the relevant data for the year 2012.

To obtain weighted average GHG footprints for Europe, we used the population statistics reported by the World Bank (2014) (see Table S1 of the ESM).

\subsection{Laundry wash model}

To assess the variability in the GHG footprint of laundry washing in the 23 European countries, we applied the functional unit of one wash cycle. Figure 2 gives an overview of the variables that were assessed in this study. GHG emissions associated with retail (e.g. consumer shopping trip); product disposal; infrastructure (e.g. construction of factories, water and energy supplies); and the manufacture of appliances were excluded and typically considered to be relatively small compared to the other life cycle phases (Dewaele et al. 2006;
Henkel AG and Co. KGAA 2009; Medyna et al. 2015; Van Hoof et al. 2003b).

The total life cycle GHG emissions per wash cycle for the 23 European countries was estimated via Eq. (1):

CFTotal $_{\mathrm{i}, \mathrm{T}, \mathrm{C}}=\mathrm{FUP}_{i} \times D_{i, C}+\mathrm{EF}_{C} \times \mathrm{EC}_{T, C}$

where CFTotal $\mathrm{i}_{\mathrm{i}, \mathrm{T}, \mathrm{C}}$ is the amount of greenhouse gas emissions associated with one wash using detergent $i$ at temperature $T$ in country $C$ in $\mathrm{g} \mathrm{CO}_{2}$-eq per wash cycle; $\mathrm{FUP}_{\mathrm{i}}$ is the GHG emission factor related to sourcing, manufacturing, packaging and transportation of product $i$ in $\mathrm{g} \mathrm{CO}_{2}$ eq per gram detergent; $D_{\mathrm{i}, \mathrm{C}}$ is the dosage of product $i$ in country $C$ in grams detergent per wash cycle, $\mathrm{EF}_{C}$ is the $\mathrm{GHG}$ emission factor of the electricity consumed in country $\mathrm{C}$ in $\mathrm{g} \mathrm{CO}_{2}-$ eq/ $\mathrm{kWh}$ and $\mathrm{EC}_{\mathrm{T}, \mathrm{C}}$ (in $\mathrm{kWh}$ ) the electricity consumption when temperature is set to $T$ in country $C$. To calculate an average GHG footprint for the 23 European countries, we weighted the average GHG emissions associated with clothes washing per country by their respective population size.

\subsection{Model simulation}

To quantify the variability of the GHG emissions from laundry washing, a Monte Carlo simulation with 100,000 runs was performed in Oracle Crystal Ball (11.1.2.4.600). To include the role of intra-country variability of temperature setting and of the detergent format relative frequency, a non-parametric bootstrapping procedure (Efron and Tibshirani 1986) was
Fig. 2 Scope of the study: boxes with thin borders show the input variables and boxes with thick borders show the variables calculated in this study

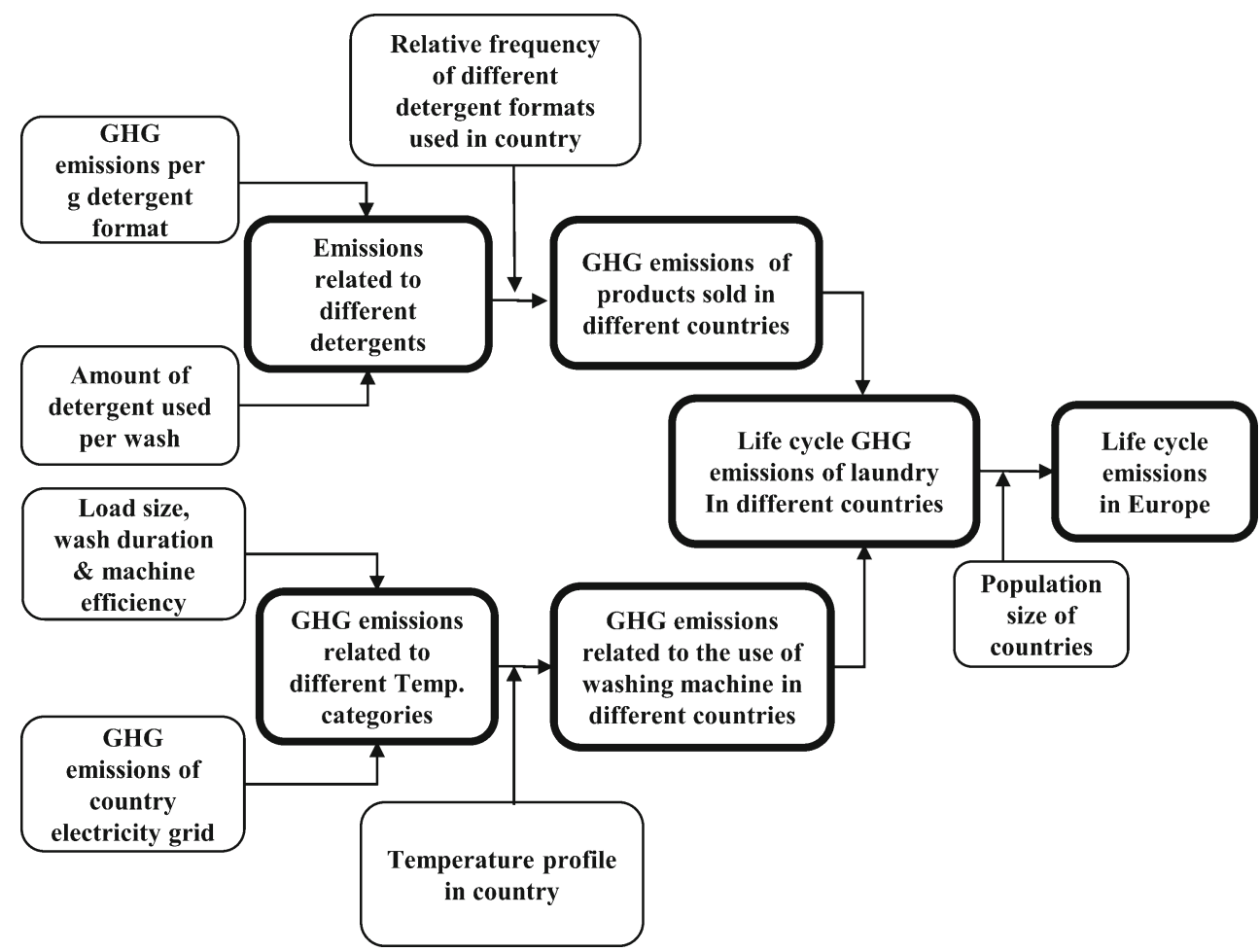


applied to develop a distribution for each country. First, we developed 23 discrete custom distributions (one for each country) each having four probability values equal to the relative frequency of the four detergent formats in the country considered. We also developed 23 discrete custom distributions (one for each country) each having four probability values equal to the share of the four temperature categories. Then, for each country and at each iteration, individual values were randomly selected for each parameter in its probability distribution and CFTotal was obtained using Eq. (1) (see more detail on the algorithm in section 2 of the ESM).

To quantify the relative influence of the various input parameters on the GHG footprint per wash cycle, we calculated Spearman rank correlation coefficients. Thenm we divided the squared rank correlation coefficient per input parameter by the sum of all squared rank correlation coefficients of the input parameters to calculate the relative contribution to the total variance of each input parameter.

\subsection{GHG reduction potential}

To assess the influence of consumer behaviour change and to estimate the reduction potential in the GHG footprint of laundry washing, we assessed a shift of all consumer washes to $30{ }^{\circ} \mathrm{C}$ or lower or the substitution of the 2014 energy mix and consumption with renewable energy from solar photovoltaic (PV) electricity. We used the GHG emission factors related to the use of solar PV systems in each country $\left(\mathrm{EF}_{\mathrm{PV}, \mathrm{C}}\right)$ instead of $\mathrm{EF}_{\mathrm{C}}$ and used the ecoinvent 3.2 database to obtain the emission factors related to the use of solar panels. The dataset represents the production of grid-connected low voltage electricity with a $3 \mathrm{~kW}$ peak building-integrated PV module (considering multi-Si panels installed on slanted roofs).

\section{Results}

\subsection{Variability in the GHG emissions of different laundry detergent formats}

Figure 3 presents the distributions of GHG emissions related to the four different product categories without considering the energy use of the washing machine. It shows that tablet detergents have the highest median GHG emissions per wash cycle $\left(1.7 \times 10^{2} \mathrm{~g} \mathrm{CO}_{2}\right.$ eq/wash cycle $)$, while the three other product categories have lower median GHG emissions $(8.4 \times$ $10^{1}-1.1 \times 10^{2} \mathrm{~g} \mathrm{CO}_{2}-\mathrm{eq} /$ wash cycle). The relatively high GHG emissions for the tablets is due to the fact that even though the quantity of tablet detergents (in gram) used per wash cycle is lower than that of powder and liquid detergents, the production of tablet ingredients is relatively carbon intensive. It can also be seen from Fig. 3 that the variability in GHG emissions related to liquid and powder detergent use is higher

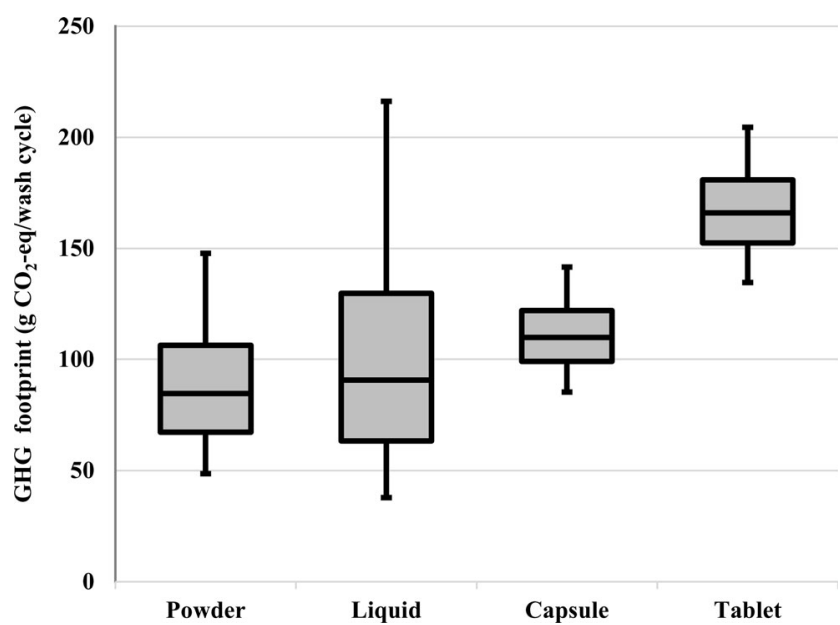

Fig. 3 Variability of the GHG emissions from the use of detergents (excluding washing machine energy use) between and within the four product categories (5th, 25th, 50th, 75th and 95th percentiles)

compared to the use of tablet and capsule detergents. That is because higher variability exists in both GHG emissions per gram detergent and dosage of powder and liquid detergents than those of tablet and capsule detergents.

\subsection{Variability in the GHG emissions associated with energy use in washing phase}

Variability in the GHG emissions due to the consumer variability in temperature selection is shown in Fig. 4. The variability is determined by the energy use of washing machines within a certain temperature category as well as the GHG emission factor of electricity production in different countries. The distributions represent the population-weighted average emissions per temperature category in Europe. The median GHG emission systematically increases from 1.5 to $5.1 \times$

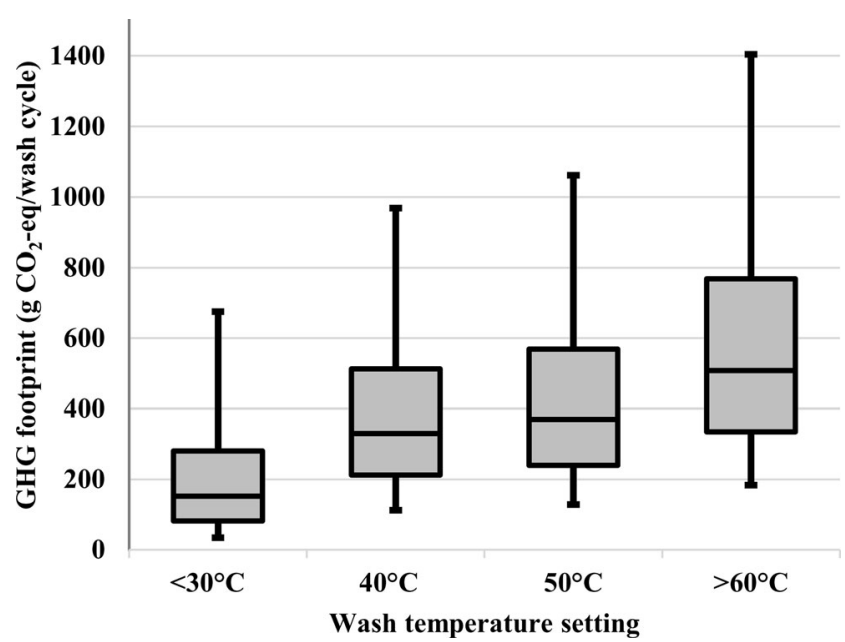

Fig. 4 Variability of the GHG emissions from washing machine use for different temperature settings. The distributions refer to a populationweighted average over all 23 European countries (5th, 25th, 50th, 75th and 95 th pdisercentiles) 
$10^{2} \mathrm{~g} \mathrm{CO}_{2}$-eq/wash cycle with increasing temperature settings from $30^{\circ} \mathrm{C}$ or lower to $60^{\circ} \mathrm{C}$ or higher. The variability within a temperature category is a factor of 8-9 (represented as the ratio of the 95 th and the 5 th percentile of the variability range), with the exception of the temperature category of $30{ }^{\circ} \mathrm{C}$ or lower which has a variability factor of 23 . The larger range is due to the fact that cold water washes (i.e., without any water heating by the machine) are also included in this category.

\subsection{Variability in the total life cycle GHG emissions}

Figure 5 presents the variability in the total life cycle GHG footprint of clothes washing in the 23 countries. To estimate the relative variability within countries we divided the 95th percentile by the 5 th percentile of each spread and to estimate between-country variability, we divided the highest median value by the lowest median value.

The median life cycle GHG emissions vary by a factor of 6.5 between the different European countries. Norway has the lowest emissions with $1.2 \times 10^{2} \mathrm{~g} \mathrm{CO}_{2}$ eq/wash cycle and Poland has the highest emissions with $7.9 \times 10^{2} \mathrm{~g} \mathrm{CO}_{2}$ eq/ wash cycle. The population-weighted average life cycle GHG emissions in Europe are equal to $5.1 \times 10^{2} \mathrm{~g} \mathrm{CO}_{2-} \mathrm{eq} /$ wash cycle. The intra-country variability due to consumer differences in detergent and energy use varies between 3.5 and 5.0, depending on the country considered.

Figure 6 shows the relative share of the machine-related parameters (use phase) from the total GHG emissions in each country. The typical relative contribution of the use phase to the GHG footprint of clothes washing in Europe ranges from 27 to $88 \%$ depending on the country considered. In addition, the relative contribution of the use phase ranges intracountries from a factor of 1.4 in Poland to a factor of 5.8 in Norway. Table S3 of the ESM provides an overview of the life cycle greenhouse gas emissions of clothes washing and the relative share of use phase reported in the literature.

\subsection{Importance analysis}

Table 2 presents the sensitivity of the variability in life cycle GHG emissions to the variability in the different input parameters of the model. For the majority of European countries, the life cycle GHG emissions are most sensitive to the variability in temperature setting $\left(\mathrm{TS}_{\mathrm{T}, \mathrm{C}}\right)$ and to the variability in energy consumption of washing machines within a specific temperature setting $\left(\mathrm{EC}_{\mathrm{T}, \mathrm{C}}\right)$. The latter is mainly influenced by duration of wash, load size, and the efficiency of washing machines. These are the countries with relativity high GHG emissions for producing electricity. For the countries with relatively low-carbon electricity generation mixes (Norway, Sweden and France), GHG emissions are most sensitive to the product-related parameters $(53-87 \%)$. The variation on machine-related parameters contributes $13-98 \%$ to the variation in life cycle GHG emissions depending on the country considered.

\subsection{GHG reduction potential}

In the case all washes were done using the temperature category of $30{ }^{\circ} \mathrm{C}$ or lower, inter-country variability would be a factor of 4.5 and the population-weighted average life cycle GHG emissions in Europe would be $330 \mathrm{~g} \mathrm{CO}_{2}$ eq/wash cycle. Given that the average GHG reduction potential of this scenario would be $177 \mathrm{~g} \mathrm{CO}_{2}$ eq/wash cycle that implies a $35 \%$ reduction in the life cycle GHG footprint of clothes washing.

In the case electricity for washing machines was generated by PV panels, inter-country variability would be as low as 1.3
Fig. 5 Life cycle GHG emissions related to one laundry wash in different European countries $\left(\right.$ CFTotal $\left._{i, T, C}\right)$ (5th, 25th, 50th, 75 th and 95th percentiles)

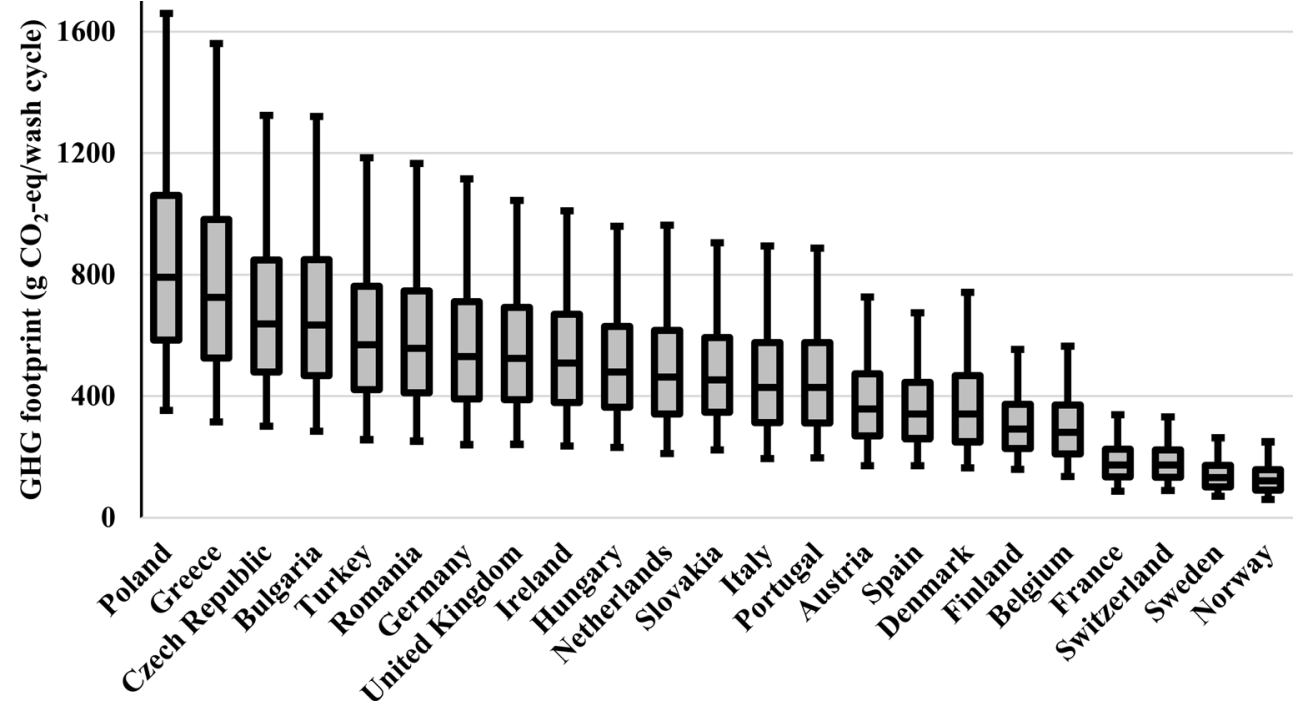


Fig. 6 Share of the GHG emissions related to the use phase from the total life cycle GHG emissions in different countries, ordered from the country with the highest median share (Poland) to the country with the lowest

(Norway) $\left(100 \% \times \mathrm{EF}_{C} \times \mathrm{EC}_{T, d}\right.$

CFTotal $_{i, T, C}$ )

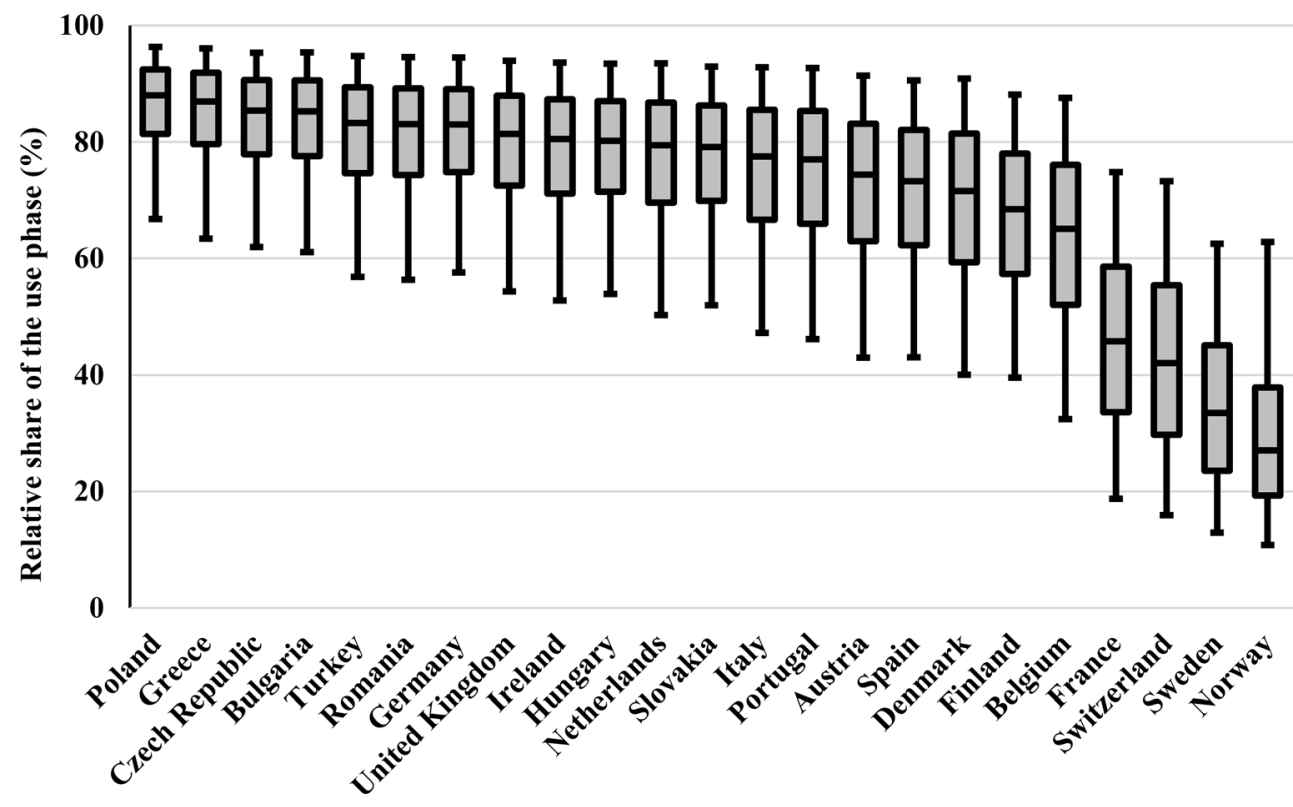

Table 2 Contribution to variance of the different parameters for each country (in percentage). For each country, the darkness of the colour of each cell shows the importance of the cell

\begin{tabular}{lcccc}
\hline \multicolumn{1}{c}{ Country } & $\begin{array}{c}\text { Detergent } \\
\text { dosage } \\
\left(\mathrm{D}_{\mathrm{i}, \mathrm{C}}\right)\end{array}$ & $\begin{array}{c}\text { Format and relative } \\
\text { frequency of detergents } \\
\left(\mathrm{FUP}_{\mathrm{i}, \mathrm{C}}+\mathrm{DF}_{\mathrm{i}, \mathrm{C}}\right)\end{array}$ & $\begin{array}{c}\text { Washing machine } \\
\text { electricity } \\
\text { consumption }\left(\mathrm{EC}_{\mathrm{T}, \mathrm{C}}\right)\end{array}$ & $\begin{array}{c}\text { Temperature } \\
\text { setting } \\
\left(\mathrm{TS}_{\mathrm{T}, \mathrm{C}}\right)\end{array}$ \\
\hline Poland & 1 & 1 & 41 & 57 \\
Greece & 1 & 1 & 34 & 65 \\
Romania & 2 & 1 & 33 & 64 \\
Bulgaria & 2 & 1 & 37 & 60 \\
Czech & 2 & 1 & 45 & 52 \\
Germany & 2 & 1 & 35 & 61 \\
Ireland & 2 & 2 & 41 & 55 \\
United Kingdom & 2 & 2 & 39 & 58 \\
Turkey & 2 & 1 & 33 & 63 \\
Hungary & 3 & 2 & 44 & 51 \\
Netherlands & 3 & 3 & 32 & 63 \\
Portugal & 3 & 2 & 30 & 65 \\
Slovakia & 4 & 2 & 45 & 49 \\
Italy & 4 & 4 & 25 & 68 \\
Spain & 5 & 4 & 36 & 56 \\
Austria & 7 & 4 & 34 & 56 \\
Denmark & 8 & 3 & 41 & 48 \\
Belgium & 9 & 8 & 24 & 59 \\
Finland & 12 & 5 & 52 & 31 \\
Switzerland & 33 & 17 & 12 & 29 \\
France & 26 & 27 & 6 & 93 \\
Sweden & 66 & 12 & & 5 \\
Norway & 65 & 22 & & 5 \\
\hline
\end{tabular}


and the population-weighted average GHG emissions in Europe would be $1.6 \times 10^{2} \mathrm{~g} \mathrm{CO}_{2}$ eq/wash cycle. This implies a threefold decrease in the life cycle GHG footprint of clothes washing. In this scenario, the product-related parameters would account for two thirds of the contribution to variance and the washing machine-related parameters would influence one third of the contribution.

\section{Discussion}

\subsection{Variability and uncertainty}

An understanding of variability and uncertainty is critical for decision-making but often poorly addressed in many LCA studies which tend to be deterministic (Ascough et al. 2008; Polizzi di Sorrentino et al. 2016). In this study, we simulated the variability in the GHG footprint of a typical household activity (i.e. laundry washing) by integrating consumer habits and survey data, using the Monte Carlo method. Various approaches and statistical treatments have been applied to estimate variability and uncertainty in LCA, such as the use of regression models in assessing life cycle inventories (Steinmann et al. 2014a) and the application of Monte Carlo methods (Steinmann et al. 2014b). Empirical studies of variability and probabilistic approaches are more commonly applied in related areas such as human and environmental risk assessment (Huizer et al. 2012). Taking consumer behaviour into account is challenging as its characterisation and measurement on significant samples of the population is complex and costly. In this study, we benefited from having access to large datasets collected by the detergent industry.

Different data collection methods such as using questionnaires, interviews, diaries, cameras and data loggers exist and each method has its own pros and cons. With regard to the choice of detergent format and temperature, we based our analysis on relatively large samples collected with questionnaires. However, behavioural data based on self-report has some limitations. Consumers often do not have sufficient insight into the drivers of habitual behaviours and will struggle to precisely remember and report on their habits (Verplanken et al. 2005). Also, social desirability may influence reporting as socially desirable behaviours tend to be over-reported in self-reports (e.g. Chung and Leung 2007). For the energy consumption, we used sensor-based data loggers that measure the actual behaviour. Such studies are more costly to implement than questionnaires and diaries but provide more reliable behavioural data. This is the reason why we were only able to include information on energy use per temperature setting for a relatively small group of 100 households in the UK only. This may limit representativeness for countries that have significantly different washing behaviours and energy consumptions beyond differences in machine temperature settings, i.e. in wash duration, load size and machine efficiency. The data also does not cover the variance in the ambient water temperature in the different countries and at different times in the year. This may lead to underestimation of variability of the GHG footprint per wash cycle within the temperature categories. Having said that, to the best of our knowledge, it is the only available measured data on consumers' real laundry washing behaviour. We compared the reported average energy consumption per temperature setting in our study with the average energy consumption in washing machines used in European countries reported by Stamminger and Schmitz (2016). In their study, the energy consumption of 50 specific models of washing machines bought from the European market between the years 2012 and 2014 was measured at 40 and $60{ }^{\circ} \mathrm{C}$. The average consumption reported in that study is consistent with the average of the figures reported in Unilever's dataset for the same programmes (both equal to $0.78 \mathrm{kWh}$ per wash cycle).

Another uncertainty is the fact that the data we used for the GHG emissions per unit of detergent was representative of the Unilever product portfolio only. However, we compared the average used in this study with the one reported by Lasic et al. (2015) and found them consistent (both $1.7 \mathrm{~g} \mathrm{CO}_{2}$ eq/g detergent). Other sources of uncertainty and variability related to the detergent dataset were not considered in this study, such as the manufacturing processes, sourcing of raw materials, and sources of energy used for manufacturing.

With regard to the dosing behaviour, we assumed consumers use only one capsule per wash and we used the capsule mass data as provided by Unilever. If more than one capsule were used, the associated GHG emissions from capsule detergents would increase accordingly. For detergent formats other than capsules, distributions of dosing amounts per wash cycle and per detergent format were available from a large consumer study in Germany. It is unknown whether this data is representative for the rest of Europe. We also did not differentiate between the use of concentrated and regular forms of liquid detergents. Based on the recommended dosages for these formats one could argue that liquid detergents should be split into different use categories. Chapotot et al. (2011) found, however, that there is no statistically significant difference between the real dosage of concentrated and regular liquid detergents. Furthermore, AISE (2014) reported that up to $40 \%$ of the consumers do not adjust their dosage behaviour according to the form of liquid detergent. Therefore, modelling the liquid detergents as one group, with a range of impacts (in $\mathrm{g} \mathrm{CO}_{2}$ eq $/ \mathrm{g}$ detergent) that covers both non-concentrated as well as concentrated forms of liquid detergents is considered justified. We did not include the possible impacts of additional products such as bleaches, fabric softeners and water softeners in this study.

We did not consider possible correlations between the input variables. According to the 'Sinner Circle' (Sinner 1960; 
Stamminger 2010), laundering performance is the result of chemistry, temperature, mechanical action from the washing machine, time and water. This means that in theory, higher average wash temperatures may have lower the dosage to reach the same performance.

Finally, to obtain the GHG emission factor of the electricity consumed in different countries $\left(\mathrm{EF}_{\mathrm{c}}\right)$, we considered electricity on the low voltage level of the different markets. However, different approaches of GHG calculation for electricity mixes will lead to different GHG emission factors. As an example, correcting the Norwegian electricity consumption for the European trade of guarantees of origin will results in a GHG emission factor of $500 \mathrm{~g} \mathrm{CO}_{2}$-eq per $\mathrm{kWh}$ for Norway (REDISS 2015).

\subsection{GHG footprint improvement potential}

Using the estimation of 34.3 billion wash loads per year in Europe by AISE (2014), we estimated a potential GHG saving of 5.9 million tonnes $\mathrm{CO}_{2-}$ eq per year from switching all washes to $30^{\circ} \mathrm{C}$ or lower. Considering $6.7 \mathrm{t}$ of $\mathrm{CO}_{2}$ emissions per capita in Europe (World Bank 2013), the saving potential equates to the total GHG emissions produced by more than 880,000 European inhabitants.

The results of the PV scenario analysis suggest that consumers can largely influence the life cycle GHG emissions of laundry detergents not only by lowering the temperature settings of the washing machine, but also by using low-carbon technologies for electricity production. Considering the number of annual wash loads in Europe, the corresponding GHG saving potential of switching to low-carbon intensive resources (in this study, we only considered PV panels) is 11.8 million tonnes $\mathrm{CO}_{2}$ eq per year. This equals to the total $\mathrm{GHG}$ emissions produced by $1,760,000$ European inhabitants.

\section{Conclusions}

The results demonstrated that in countries with carbonintensive electricity sources, the variability in life cycle GHG emissions is most sensitive to the variability in machine-related parameters, such as the temperature setting. However, in countries with low-carbon electricity sources, GHG emissions are most sensitive to the product-related parameters, such as the type and amount of detergent applied.

Given the importance of the role of variability in consumer behaviour in LCA studies, using a combination of different data collection methods would help in producing data of higher quality and representativeness. This would lead to a more accurate quantification of the environmental impacts associated with daily activities and enable more targeted measures for the reduction of the environmental footprint of consumer goods. The use of a combination of rich data sources enabled us to quantify the variability in the life cycle GHG emissions of a household activity which is caused by variety of consumer choices, manufacturer choices and infrastructural differences of countries.

While the presented results are limited to GHG emissions, a similar approach can be used for the quantification of other environmental impacts in particular to highlight tradeoffs that may be associated with particular choices. Besides, the application of this method to other household activities could be of interest for future studies.

Acknowledgments This project has received funding from the European Union's Horizon 2020 research and innovation programme under the Marie Sklodowska-Curie grant agreement No 641459 (RELIEF). This research has made use of the Pan-European consumption survey on sustainability and washing habits commissioned by the International Association for Soaps, Detergents and Maintenance Products (AISE).

Open Access This article is distributed under the terms of the Creative Commons Attribution 4.0 International License (http:// creativecommons.org/licenses/by/4.0/), which permits unrestricted use, distribution, and reproduction in any medium, provided you give appropriate credit to the original author(s) and the source, provide a link to the Creative Commons license, and indicate if changes were made.

\section{References}

AISE (2013) The case for the "A.I.S.E. low temperature washing" initiative, Substantiation Dossier, A.I.S.E. www.aise.eu

AISE (2014) Washing habits, usage, and attitude (Confidential Table Report), www.aise.eu

AISE (2015) PEF screening report in the context of the EU product environmental footprint category rules (PEFCR) pilots, household heavy duty liquid laundry detergents (HDLLD) for machine wash, https://webgate.ec.europa.eu/fpfis/wikis/pages/viewpage.action? spaceKey=EUENVFP\&title=EU+Environmental+Footprint+Pilot + Phase

Ascough JC, Maier HR, Ravalico JK, Strudley MW (2008) Future research challenges for incorporation of uncertainty in environmental and ecological decision-making. Ecol Model 219(3):383-399. https://doi.org/10.1016/j.ecolmodel.2008.07.015

Chapotot E, Abi Akle A, Minel S, Yannou B (2011) Comparative study of theoretical and real uses of eco-designed laundry detergents. In DS 68-6: proceedings of the 18th international conference on engineering design (ICED 11), impacting society through engineering design, Vol. 6: design information and knowledge, Lyngby/ Copenhagen, Denmark

Chung SS, Leung M (2007) The value-action gap in waste recycling: the case of undergraduates in Hong Kong. Environ Manag 40(4):603612. https://doi.org/10.1007/s00267-006-0363-y

de Koning A, Schowanek D, Dewaele J, Weisbrod A, Guinée J (2010) Uncertainties in a carbon footprint model for detergents; quantifying the confidence in a comparative result. Int J Life Cycle Assess 15(1): 79-89. https://doi.org/10.1007/s11367-009-0123-3

Dewaele J, Pant R, Schowanek D (2006) Comparative life cycle assessment (LCA) of Ariel "Actif à froid"(2006), a laundry detergent that allows to wash at colder wash temperatures, with previous Ariel laundry detergents $(1998,2001)$ Procter \& Gamble, Brussels Innovation Center, Central Product Safety-Environmental, Brussels 
Efron B, Tibshirani R (1986) Bootstrap methods for standard errors, confidence intervals, and other measures of statistical accuracy. Stat Sci 1(1):54-75. https://doi.org/10.1214/ss/1177013815

Golsteijn L, Menkveld R, King H, Schneider C, Schowanek D, Nissen S (2015) A compilation of life cycle studies for six household detergent product categories in Europe: the basis for product-specific AISE charter advanced sustainability profiles. Environ Sci Eur 27: $1-12$

Hellweg S, Milà i canals L (2014) Emerging approaches, challenges and opportunities in life cycle assessment. Science 344(6188):1109 1113. https://doi.org/10.1126/science.1248361

Henkel AG \& Co. KGAA (2009) Case study persil megaperls: case study undertaken within the PCF pilot project Germany

Huizer D, Oldenkamp R, Ragas AM, van Rooij JG, Huijbregts MA (2012) Separating uncertainty and physiological variability in human PBPK modelling: the example of 2-propanol and its metabolite acetone. Toxicol Lett 214(2):154-165. https://doi.org/10.1016/j. toxlet.2012.08.016

Koehler A, Wildbolz C (2009) Comparing the environmental footprints of home-care and personal-hygiene products: the relevance of different life-cycle phases. Environ Sci Technol 43(22):8643-8651. https://doi.org/10.1021/es901236f

Koerner M, Schulz M, Powell S, Ercolani M (2011) The life cycle assessment of clothes washing options for city west water's residential customers. In: proceedings of the 7th Australian life cycle assessment conference. Melbourne. Retrieved May, 2011. P 2013

Kruschwitz A, Karle A, Schmitz A, Stamminger R (2014) Consumer laundry practices in Germany. Int J Consum Stud 38(3):265-277. https://doi.org/10.1111/ijcs.12091

Laitala K, Boks C, Klepp IG (2011) Potential for environmental improvements in laundering. Int J Consum Stud 35(2):254-264. https://doi. org/10.1111/j.1470-6431.2010.00968.x

Lasic E, Stamminger R, Nitsch C, Kessler A (2015) Construction of a virtual washing machine. Tenside Surfact Det 52(3):193-200. https://doi.org/10.3139/113.110365

Lin J, Iyer M (2007) Cold or hot wash: technological choices, cultural change, and their impact on clothes-washing energy use in China. Energ Policy 35(5):3046-3052. https://doi.org/10.1016/j.enpol. 2006.11.001

Market Transformation Programme (2010) UK domestic energy use over time: Total electricity consumption by household domestic appliances. UK

Masanet E (2010) Assessment of household carbon footprint reduction potentials. Lawrence Berkeley National Laboratory

Medyna G, Larriba AB, Kaps RB, Arendorf J, Bojczuk K, Sims E, Gaasbeek A (2015) Revision of the EU ecolabel criteria for: laundry detergents and industrial and institutional laundry detergents. Preliminary Report. Institute for Prospective and Technological Studies, Joint Research Centre

Nielsen AM, Li H, Zhang H (2013) Compact detergents in China - a step towards more sustainable laundry H\&PCToday 8:30-35

Novem S (2001) Revision of energy labelling \& targets washing machines (clothes) study for the directorate-general TREN of the Commission of the European Communities, The Netherlands

Pakula C, Stamminger R (2010) Electricity and water consumption for laundry washing by washing machine worldwide. Energ Effic 3(4): 365-382. https://doi.org/10.1007/s12053-009-9072-8

Pakula C, Stamminger R (2015) Energy and water savings potential in automatic laundry washing processes. Energ Effic 8(2):205-222. https://doi.org/10.1007/s12053-014-9288-0
Polizzi di Sorrentino E, Woelbert E, Sala S (2016) Consumers and their behavior: state of the art in behavioral science supporting use phase modeling in LCA and ecodesign. Int J Life Cycle Assess 21(2):237251. https://doi.org/10.1007/s11367-015-1016-2

Presutto M, Stamminger R, Scaldoni R, Mebane W, Esposito R (2007) Preparatory study of eco-design requirements of EuPs; lot 14: domestic washing machines and dishwashers; task 3-5 ISIS

RE-DISS (2015) Country profiles 2015, Downloadable from (http:// www.reliable-disclosure.org/documents/\#thema3)

Rubinstein RY, Kroese DP (2016) Simulation and the Monte Carlo method. John Wiley \& Sons. doi: https://doi.org/10.1002/ 9781118631980

Saouter E, Van Hoof G, Feijtel T, Stalmans M, Uhl J, Vollebergt L, Westra J (1998) Life cycle inventory on laundry detergents: analysis of the LCI profiles of liquid and powder detergents. In: 38th WFK international detergency conference, Seidenweberhaus, Krefeld, Germany

Sinner H (1960) Ueber das Waschen mit Haushaltwasmaschinen: in welchem Umfange erleichtern Haushaltwaschmachinen undgeraete das Waeschehaben im Haushalt? Haus und Heim-Verlag

Stamminger R (2010) Reinigen Lebensmittelverarbeitung im Haushalt, aid-Verlag:307-334

Stamminger R, Schmitz A (2016) Washing machines in Europe-detailed assessment of consumption and performance. Tenside Surfact Det 53(1):70-86. https://doi.org/10.3139/113.110412

Steinmann ZJ, Venkatesh A, Hauck M, Schipper AM, Karuppiah R, Laurenzi IJ, Huijbregts MA (2014a) How to address data gaps in life cycle inventories: a case study on estimating $\mathrm{CO} 2$ emissions from coal-fired electricity plants on a global scale. Environ Sci Technol 48(9):5282-5289. https://doi.org/10.1021/es500757p

Steinmann ZJ, Hauck M, Karuppiah R, Laurenzi IJ, Huijbregts MA (2014b) A methodology for separating uncertainty and variability in the life cycle greenhouse gas emissions of coal-fueled power generation in the USA. Int J Life Cycle Assess 19(5):1146-1155. https://doi.org/10.1007/s11367-014-0717-2

Throne-Holst H, Stø E, Strandbakken P (2007) The role of consumption and consumers in zero emission strategies. J Clean Prod 15(13): 1328-1336. https://doi.org/10.1016/j.jclepro.2006.07.018

Tomlinson JJ, Rizy D (1998) Bern clothes washer study. Final report. Oak Ridge National Lab, TN, USA

Van Hoof G, Schowanek D, Feijtel TC, Boeije G, Masscheleyn PH (2003) Comparative life-cycle assessment of laundry detergent formulations in the UK. Part II: time trend analysis and wash equivalent comparison (1988-2001). Tenside Surfact Det 40:276-287

Verplanken B, Myrbakk V, Rudi E (2005) The measurement of habit. In: The routines of decision making. Lawrence Erlbaum, Mahwah, pp 231-247

Weidema BP, Bauer Ch, Hischier R, Mutel Ch, Nemecek T, Reinhard J, Vadenbo CO, Wernet G (2013) The ecoinvent database: overview and methodology, Data quality guideline for the ecoinvent database version 3, www.ecoinvent.org

World Bank (2013) CO2 emissions, http://data.worldbank.org/indicator/ EN.ATM.CO2E.PC?year_high_desc=true

World Bank (2014) Total population, http://data.worldbank.org/indicator/ SP.POP.TOTL

Yao R, Steemers K (2005) A method of formulating energy load profile for domestic buildings in the UK. Energ Buildings 37(6):663-671. https://doi.org/10.1016/j.enbuild.2004.09.007

Zaraket T (2014) Stochastic activity-based approach of occupant-related energy consumption in residential buildings. Dissertation, Engineering Sciences. Ecole Centrale Paris 